\title{
Antagonistic Activity and the Mechanism of Bacillus amyloliquefaciens DH-4 Against Citrus Green Mold
}

\author{
Kai Chen, Zhonghuan Tian, Yuan Luo, Yunjiang Cheng, and Chao-an Long ${ }^{\dagger}$
}

All authors: Key Laboratory of Horticultural Plant Biology of the Ministry of Education, National Centre of Citrus Breeding, Huazhong Agricultural University, Wuhan 430070, P. R. China; and first author: Center of Applied Biotechnology, Wuhan Institute of Bioengineering, Wuhan 430415, P. R. China.

Accepted for publication 23 May 2018.

\begin{abstract}
Citrus fruit usually suffer significant losses during the storage and transportation stages. Green mold, a postharvest rot of citrus fruit caused by Penicillium digitatum, is one of the most serious fungal diseases. In this study, the antagonist strain DH-4 was identified as Bacillus amyloliquefaciens according to morphological observation and 16S ribosomal DNA analysis. In addition, it showed broad antifungal activity, especially the suppression of Penicillium spp. The culture filtrate of strain DH-4 exhibited apparent activity against $P$. digitatum in vitro and in vivo. In storage, the culture filtrate with DH-4 in it showed a better antiseptic effect. The antifungal substances in the culture filtrate, produced by strain DH-4, displayed stable activity in various extreme conditions. In addition, the antifungal substances in the culture filtrate were identified as macrolactin, bacillaene, iturins, fengycin, and surfactin by ultraperformance liquid

chromatography (UPLC) electrospray ionization mass spectrometry analysis. The UPLC fractions containing these antifungal compounds were basically heat tolerant and all responsible for the antagonistic activity against $P$. digitatum. Transmission electron microscope observation indicated that the antifungal substances might cause abnormalities in the $P$. digitatum cellular ultrastructure, which could be the possible mode of action of $B$. amyloliquefaciens against $P$. digitatum. In addition, it was confirmed via scanning electron microscope analysis that the main way it inhibited $P$. digitatum was by secreting antimicrobial compounds without direct interaction. This study contributes to the understanding of the mechanism of $B$. amyloliquefaciens against citrus green mold as well as providing a potential application for the biocontrol of postharvest rot diseases in citrus fruit.
\end{abstract}

Citrus fruit is an economically important fruit and usually suffers significant losses during the storage and transportation stages. Green mold, caused by Penicillium digitatum, is one of the most serious postharvest fungal diseases in citrus (Arcas et al. 2000). This pathogenic necrotrophic fungus has attracted increasing attention around the world. Chemical control methods have been broadly used to control plant diseases for a long time. However, because chemical fungicides can threaten human health, potentially damage the environment, and induce drug resistance in microbes (Marcet-Houben et al. 2012), the development of novel control approaches is urgent, especially biological control approaches (Janisiewicz and Korsten 2002).

Yeast and Bacillus spp. were widely used for selecting antagonists. Yeasts played a very important role in postharvest biocontrol. Blue mold and green mold can be controlled by Pichia membranifaciens (Luo et al. 2012). Yeasts such as Candida oleophila, Debaryomyces hansenii, Kloeckera apiculata, Metschnikowia fructicola, and Rhodotorula glutinis, among others, have also been identified as antagonists (Sharma et al. 2009). The abilities of Bacillus spp. as biocontrol agents have been studied and reported for several years (Szczech and Shoda 2006; Yánez-Mendizábal et al. 2012). Bacillus amyloliquefaciens has a great potential to control a variety of plant pathogens (Zhao et al. 2013). B. pumilus was reported to significantly

${ }^{\dagger}$ Corresponding author: Chao-an Long; E-mail: postharvest@mail.hzau.edu.cn

Funding: This research was financially supported by the National Natural Science Foundation of China (grant number 31672205), the earmarked fund for China Agriculture Research System CARS-26, and the National Key Research and Development Program (program number 2016YFD0400904).

*The $\boldsymbol{e}$-Xtra logo stands for "electronic extra" and indicates that one supplementary table is published online.

(C) 2018 The American Phytopathological Society inhibit the infection of Penicillium digitatum in Valencia orange (Huang et al. 1992). Paenibacillus polymyxa demonstrated a suppression effect on the conidial germination of Penicillium digitatum in citrus (Lai et al. 2012).

The antimicrobial mechanisms of Bacillus spp. have been well analyzed. The most common discovery was the production of active antimicrobial compounds that directly inhibit diseases (Monteiro et al. 2005). These compounds have been purified and identified. The cyclic lipopeptides (CLP) (surfactin, fengycin, and iturin) were found to control the clubroot disease of crucifers, and the CLP were possibly one of the main antimicroorganism mechanisms of B. subtilis XF-1 (Li et al. 2014). B. amyloliquefaciens Q-426 generated bacillomycin D, fengycin A, and fengycin B to completely inhibit the spore germination of Fusarium oxysporum (Zhao et al. 2013). The antibacterial substances macrolactin A, 7-O-malonyl macrolactin A, and surfactin B were produced by B. amyloliquefaciens HR62 to prevent the growth of Ralstonia solanacearum (Huang et al. 2014). B. amyloliquefaciens ES-2 was also a coproducer of surfactins and fengycins (Sun et al. 2006). Additionally, the culture filtrate of Bacillus spp. had a positive effect in a previous study. For timber producers, sapstain was a major problem. The filtrate of B. amyloliquefaciens CGMCC 5569 showed growth inhibition activity against some sapstain fungi, which could be utilized as a bioresource (Yuan et al. 2012).

The aim of this study was to analyze the antagonistic characteristics and the antifungal mechanism of $B$. amyloliquefaciens strain DH-4 and its culture filtrate against citrus green mold. This will facilitate the application of strain DH-4 in the horticultural field and promote the exploration of the potential of the culture filtrate as a biofungicide.

\section{MATERIALS AND METHODS}

Strains and culture media. The strain DH-4 was isolated from rhizosphere soil of citrus at Huazhong Agricultural University, 
China. The antagonist and the 18 fungal strains (used in this study) were cultured in potato dextrose agar (PDA) medium (20\% potato extract, $2 \%$ dextrose, and $2 \%$ agar) at $28^{\circ} \mathrm{C}$ (Table 1 ).

Citrus fruit. FuBen navel orange fruit and Newhall navel orange fruit were harvested from the orchard of Huazhong Agricultural University, China. After being disinfected with $2 \% \mathrm{NaClO}$, the fruit were washed with distilled water and then air dried for use.

Screening antagonist. The candidate strains used for the antifungal ability assay were cultured in PDA media at $28^{\circ} \mathrm{C}$ and shaken at $180 \mathrm{rpm}$. After incubating for $36 \mathrm{~h}$, the supernatants were collected by centrifugation and filtered through a $0.22-\mu \mathrm{m}$ microfiltration membrane to remove the microbes. The culture filtrates were used for the antifungal activity assay.

The $100-\mu$ spore suspension of $P$. digitatum $\left(1 \times 10^{6} \mathrm{CFU} / \mathrm{ml}\right)$ was mixed with $100 \mathrm{ml}$ of melting PDA media (at a moderate temperature that did not kill $P$. digitatum) and poured into the petri dishes. First, agar lawns with the candidate strains were pasted on the center of the petri dishes. Second, a $0.5-\mathrm{cm}$ well in the center of the petri dishes was created using a hole puncher, and $20 \mu \mathrm{l}$ of culture filtrate was added to the hole. Sterile potato dextrose broth (PDB) solution was used as the control. After being cultured for 3 days, the inhibitory zone of each strain appeared. This experiment was carried out in triplicate. Strain DH-4 showed significant inhibitive activity against $P$. digitatum and could be used as an antagonist.

Identification of strain DH-4. Morphological observation. First, $1 \times 10^{6} \mathrm{CFU} / \mathrm{ml}$ of the strain $\mathrm{DH}-4$ was diluted using a gradient, and $50 \mu \mathrm{l}$ of diluent was coated on a PDA plate and cultured at $28^{\circ} \mathrm{C}$ for $36 \mathrm{~h}$. The morphology of the cells and a single colony were observed.

Molecular identification and phylogenetic tree construction. Strain DH-4 cultured in PDB at $28^{\circ} \mathrm{C}$ for $36 \mathrm{~h}$ was collected by centrifugation at $10,000 \mathrm{rpm}$ for $10 \mathrm{~min}$. Total DNA was extracted following the method described in a previous study (Xia et al. 2005). The 16 S ribosomal DNA (rDNA) was amplified by using a universal primer pair: forward 8f: 5'-AGAGTTTGATC CTGGCTCAG-3' and reverse rp2: 5' -ACGGCTACCTTGTTACGA CTT-3'. The polymerase chain reaction (PCR) conditions were as follows: initial denaturation at $94^{\circ} \mathrm{C}$ for $5 \mathrm{~min}$; denaturation at $94^{\circ} \mathrm{C}$ for $1 \mathrm{~min}$, annealing at $58^{\circ} \mathrm{C}$ for $1 \mathrm{~min}$, and an extension at $72^{\circ} \mathrm{C}$ for $2 \mathrm{~min}$ for 35 cycles; and a terminal extension at $72^{\circ} \mathrm{C}$ for $10 \mathrm{~min}$. The PCR product was sequenced. The sequence was submitted to the National Center for Biotechnology Information website to perform BLAST for a homologous search against microbial genomes. In total, 12 sequences from the matched results were used to construct the phylogenetic tree of strain DH-4 with the software MEGA 6.

Antifungal effect of $B$. amyloliquefaciens DH-4 in vitro. For the antifungal spectrum assay, 17 fungal strains $(P$. digitatum N1, P. digitatum P44, P. italicum B3, P. italicum A10, P. italicum $\mathrm{P} 6$,
P. chrysogenum $\mathrm{B} 5$, P. chrysogenum $\mathrm{Q}$, P. polonicum $\mathrm{A} 1$, P. ulaiense $\mathrm{Pu}, P$. expansum L, P. crustosum $\mathrm{B} 1$, Geotrichum citri-aurantii AY1, Alternaria citri A31-2-1, Phomopsis citri MT, Botryosphaeria dothidea Ahau, Colletotrichum gloeosporioides AISH, and Aspergillus niger Fen) were evaluated using the procedures for screening antagonists, and $20 \mu \mathrm{l}$ of sterile PDB was used as the control. The diameter of each inhibition zone was measured after cultivation for 5 days. Each treatment was carried out for three replications.

Inhibition testing in vivo. Two wounds at a $5-\mathrm{mm}$ depth were made at the waist of citrus fruit by using a bodkin. The wounds were inoculated with the following treatments: (i) control, $20 \mu \mathrm{l}$ of Penicillium digitatum spore suspension $\left(1 \times 10^{6} \mathrm{CFU} / \mathrm{ml}\right)$; (ii) $20 \mu \mathrm{l}$ of $P$. digitatum spore suspension and $20 \mu \mathrm{l}$ of DH-4 cell suspension (without culture filtrate, $1 \times 10^{6} \mathrm{CFU} / \mathrm{ml}$ ); and (iii) $20 \mu \mathrm{l}$ of
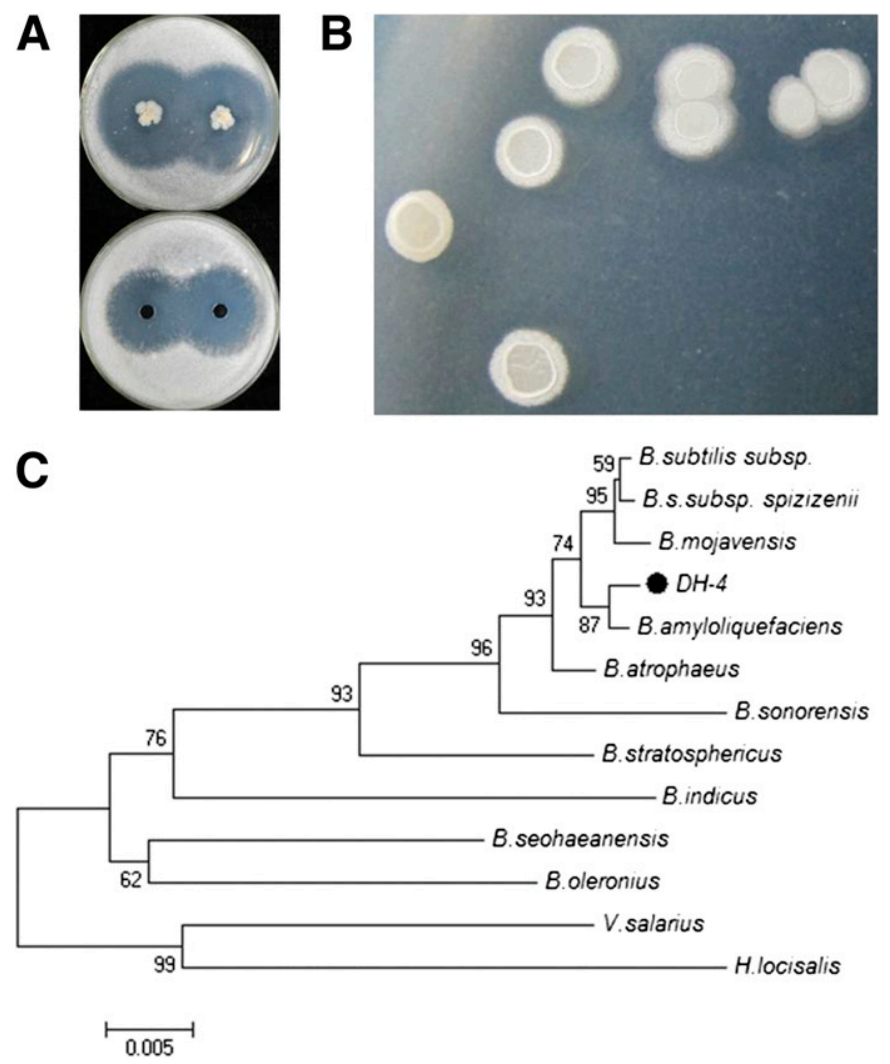

Fig. 1. Screening and identification of the strain DH-4. A, Inhibition effect of the strain DH-4 against Penicillium digitatum N1; B, single colony; C, phylogenetic tree based on $16 \mathrm{~S}$ ribosomal DNA of strain DH-4.

TABLE 1. Inhibition effect of Bacillus amyloliquefaciens DH-4 against 17 fungi

\begin{tabular}{|c|c|c|}
\hline Strain & Diameter of inhibition zone $(\mathrm{cm}) \pm \mathrm{SE}$ & Source \\
\hline Penicillium digitatum N1 & $5.56 \pm 0.05$ & Zhejiang, China \\
\hline P. digitatum $\mathrm{P} 44$ & $6.07 \pm 0.11$ & Italy \\
\hline P. italicum B3 & $6.19 \pm 0.07$ & Hubei, China \\
\hline P. italicum A10 & $4.74 \pm 0.21$ & Hubei, China \\
\hline P. italicum $\mathrm{P6}$ & $3.22 \pm 0.07$ & Italy \\
\hline P. chrysogenum B5 & $2.32 \pm 0.06$ & Hubei, China \\
\hline P. chrysogenum $\mathrm{Q}$ & $2.32 \pm 0.1$ & Hubei, China \\
\hline P. polonicum A1 & $2.65 \pm 0.08$ & Hubei, China \\
\hline P. ulaiense $\mathrm{Pu}$ & $6.35 \pm 0.07$ & Italy \\
\hline P. expansum $\mathrm{L}$ & $2.02 \pm 0.05$ & Hubei, China \\
\hline P. crustosum B1 & $2.53 \pm 0.1$ & Hubei, China \\
\hline Geotrichum citri-aurantii AY-1 & $1.89 \pm 0.02$ & Hubei, China \\
\hline Alternaria citri A31-2-1 & $2.4 \pm 0.02$ & Hubei, China \\
\hline Phomopsis citri MT & $2.77 \pm 0.05$ & Hubei, China \\
\hline Botryosphaeria dothidea Ahau & $3.04 \pm 0.12$ & Anhui, China \\
\hline Colletotrichum gloeosporioides AISH & $4.28 \pm 1.1$ & Hubei, China \\
\hline Aspergillus niger Fen & $3.17 \pm 0.42$ & Hubei, China \\
\hline
\end{tabular}


$P$. digitatum spore suspension and $20 \mu \mathrm{l}$ of DH- 4 culture filtrate. These fruit were stored in a plastic fresh-keeping box $(15$ by $25 \mathrm{~cm})$ at $26^{\circ} \mathrm{C}$ with a relative humidity of approximately $90 \%$. Each treatment was done in three replications, and six fruit were used for each replication.

Storage experiment. Newhall navel orange fruit were soaked for 2 min with the following treatments: (i) DH-4 cell suspension (noncentrifuged fermentation, $1 \times 10^{6} \mathrm{CFU} / \mathrm{ml}$ ); (ii) $\mathrm{DH}-4$ culture filtrate; (iii) control (distilled water). Then, the fruit were air dried and each fruit was put in a storage bag. The fruit were directly stored in a ventilated warehouse (approximately 5 to $10^{\circ} \mathrm{C}$ ) for a natural storage test. Visual decay was evaluated after 2 months of storage. Each treatment was replicated 10 times, and 100 fruit were used for each replication.

Antifungal stability analysis of the culture filtrate. The agar diffusion assays were carried out to evaluate the antifungal stability of the culture filtrate and included a heat treatment, a light treatment, volatility testing, and different $\mathrm{pH}$ values, with an untreated filtrate as the control. Each treatment was done in three replications.

For heat tolerance, $1 \mathrm{ml}$ of sterile filtrate was subjected to $100^{\circ} \mathrm{C}$ for $30 \mathrm{~min}$ and then cooled to $20^{\circ} \mathrm{C}$ for bioassay.

For the light treatment, $100 \mu \mathrm{l}$ of culture filtrate was put into one well of a 24-well cell culture plate, and the experiment was performed three times. One plate was exposed to direct sunlight for $30 \mathrm{~min}$ and another to $365-\mathrm{nm}$ UV light for $30 \mathrm{~min}$ at a distance of $10 \mathrm{~cm}$.

For volatility testing, three $100-\mu l$ plates of filtrate were exposed at room temperature for $1 \mathrm{~h}$.

For different $\mathrm{pH}$ values, filtrates were adjusted to $\mathrm{pH} 3,5,7,9$, and 11 using $0.5 \mathrm{M} \mathrm{HCl}$ and $\mathrm{NaOH}$ and placed at room temperature for $24 \mathrm{~h}$. Next, the samples and the $\mathrm{pH}$ control group (no $\mathrm{pH}$ adjustment) were adjusted to $\mathrm{pH} 7$ for bioassay.

Purification and ultraperformance liquid chromatography/ electrospray ionization mass spectrometry analysis of antifungal substances. The culture filtrate of Bacillus amyloliquefaciens DH-4 $(200 \mathrm{ml})$ was extracted three times in an equal volume by ethyl acetate. The ethyl acetate phase was concentrated using a rotary evaporator, and the residues were dissolved in $10 \mathrm{ml}$ methanol for bioassay and analysis of antifungal substances.

The extract was subjected to an ultraperformance liquid chromatography (UPLC) (Waters Acquity UPLC) electrospray ionization mass spectrometry (ESI-MS) (Waters XEVO TQD) system with a C18 column $(1.7 \mu \mathrm{m}, 2.1$ by $100 \mathrm{~mm}$; Waters Acquity UPLC BEH). The temperature of the column was $40^{\circ} \mathrm{C}$. The sample was eluted by the mobile phase, consisting of $0.2 \%$ acetic acid in water (A) and $0.2 \%$ acetic acid in acetonitrile (B), with a flow rate at $0.45 \mathrm{ml} / \mathrm{min}$. The gradient program was as follows: 0 to $0.2 \mathrm{~min}$,

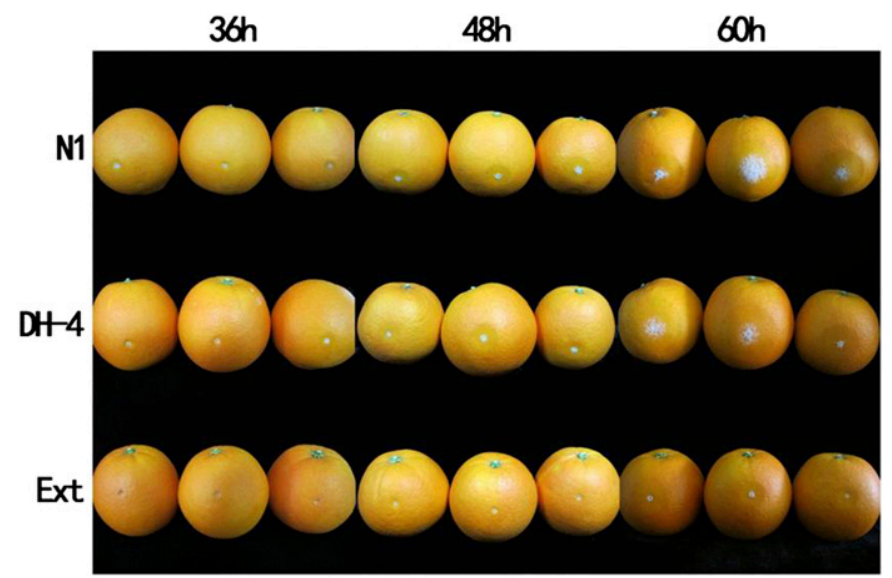

Fig. 2. Inhibition effect of DH-4 against green mold in vivo. The citrus fruit treated with Penicillium digitatum strain N1, P. digitatum strain $\mathrm{N} 1$ and the strain of DH-4, and $P$. digitatum strain N1 and the culture filtrate of DH-4 are indicated as N1, DH-4, and Ext, respectively.
95\% $\mathrm{A}$ and $5 \% \mathrm{~B} ; 0.2$ to $8.2 \mathrm{~min}, 95$ to $0 \% \mathrm{~A}$ and 5 to $100 \% \mathrm{~B} ; 8.2$ to $9.7 \mathrm{~min}, 100 \% \mathrm{~B} ; 9.7$ to $11.30 \mathrm{~min}, 100$ to $5 \% \mathrm{~B}$ and 0 to $95 \% \mathrm{~A}$; and 11.30 to $13.00 \mathrm{~min}, 95 \% \mathrm{~A}$ and $5 \% \mathrm{~B}$. For the MS analysis, the eluted fractions were measured in both positive- and negative-ion modes to determine the molecular weights. The electrospray source for $\mathrm{ESI}^{+}$was operated at a capillary voltage of $3.5 \mathrm{kV}$, a cone voltage of $46 \mathrm{~V}$, a desolvation temperature of $450^{\circ} \mathrm{C}$, and a gas flow of 1,000 liters/h. The different part for $\mathrm{ESI}^{-}$was the capillary voltage at $2.5 \mathrm{kV}$.

Bioassay of different fractions in culture filtrate. The extract of the culture filtrate was subjected to the semipreparative UPLC system. The antimicrobial compounds were separated, and 17 fractions at the peaks were collected and dried. Then, the residues were dissolved in $500 \mu \mathrm{l}$ of methanol for inhibition assay against $P$. digitatum.

Antifungal role of the heat-killed fractions. The 17 fractions were treated at $100^{\circ} \mathrm{C}$ for $30 \mathrm{~min}$. Then these heat-killed fractions were used to test the antifungal role against $P$. digitatum.

Antagonistic modes of action analysis. Scanning electron microscope observation in vivo. Citrus tissue samples ( 5 by $5 \mathrm{~mm}$ ) were collected from the orange lesion (treated as such in an inhibition test in vivo) with a scalpel at the time points of $3,8,24$, and $36 \mathrm{~h}$ after inoculation. These samples were fixed in $2.5 \%$ glutaraldehyde at $4^{\circ} \mathrm{C}$ overnight. The samples were washed and fixed in $1 \% \mathrm{OsO}_{4}$ for $2 \mathrm{~h}$, and the samples were dehydrated with concentration-increasing alcohol and dried using the method of critical-point drying (Zhang et al. 2013). The specimens were immediately gold-palladium sputtered and photographed with the scanning electron microscope (SEM) platform (JSM-6390 LV; JEOL) of HZAU, China (Liu et al. 2014b).

Action site detection. First, $200 \mu \mathrm{l}$ of $P$. digitatum spore suspension $\left(1 \times 10^{6} \mathrm{CFU} / \mathrm{ml}\right)$ was inoculated into $50 \mathrm{ml}$ of sterile PDB media and shaken at $180 \mathrm{rpm}$ for $24 \mathrm{~h}$. Next, $200 \mu \mathrm{l}$ of culture filtrate of DH-4 was added to the flask $(200 \mu \mathrm{l}$ of sterile water was used as the control). After being cultured for $0,0.5,1$, and $2 \mathrm{~h}$, the cells of $P$. digitatum were observed by a transmission electron microscope (TEM) (JEOL H-7650; Hitachi High-Technologies Co.). The method of preparing a TEM section was completed following a previous report (Liu et al. 2014a). We performed this experiment twice.

Statistical analysis. The statistical analysis was conducted using the Statistical Program SAS V8 for Windows. Data were expressed as mean \pm standard error. Analysis of variance was performed and groups were compared by $t$ test to identify significance of difference between groups. $P$ value $=0.05$ was considered statistically significant.

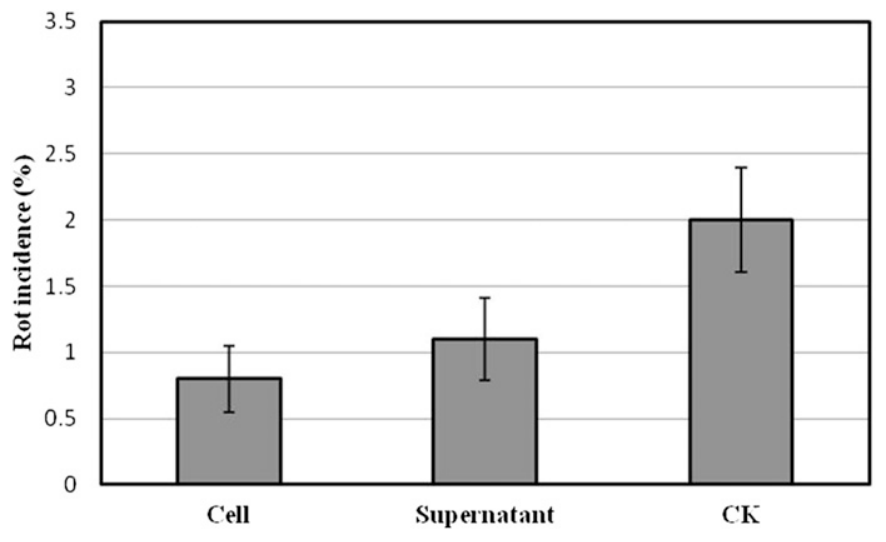

Fig. 3. Antiseptic effect in storage. Fruit treated with DH-4 cell fermentation, DH-4 supernatant, and distilled water are indicated as Cell, Supernatant, and CK, respectively. 


\section{RESULTS}

Screening and identification of the antagonist. The strain DH-4 was selected as an antagonist. Strain DH-4 and its culture filtrate showed apparent inhibition activity against $P$. digitatum $\mathrm{N} 1$
(Fig. 1A). A clear inhibitory zone appeared between strain DH-4 and N1. A single colony of the strain DH-4 was milky in color, with a circular, wrinkled protuberance around the edge on the PDA plates (Fig. 1B). The $16 \mathrm{~S}$ rDNA sequence $(1,432 \mathrm{bp})$ was deposited in GenBank with accession number KP313602. The comparison

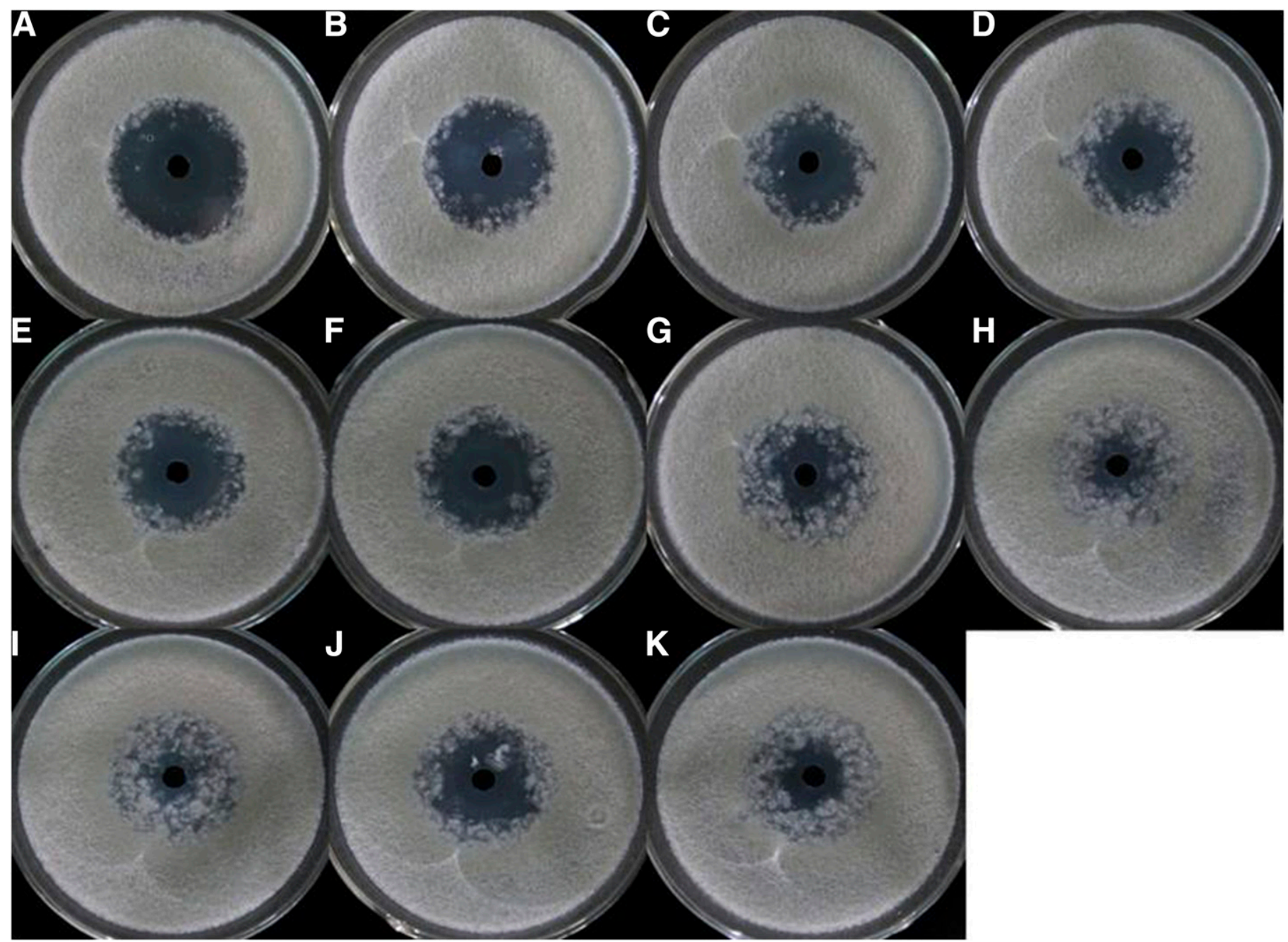

Fig. 4. Stability of the culture filtrate of DH-4. Culture filtrates of strain DH-4 were subjected to various stresses for the stability assay of the antifungal activity. A, Control without any treatment; $\mathbf{B}$, heat treatment; $\mathbf{C}$, UV irradiation; D, sunlight irradiation; E, volatilization; $\mathbf{F}, \mathrm{pH}$ control group; $\mathbf{G}, \mathrm{pH} 3 ; \mathbf{H}, \mathrm{pH} 5 ; \mathbf{I}, \mathrm{pH} 7 ; \mathbf{J}, \mathrm{pH}$ 9; and $\mathbf{K}, \mathrm{pH} 11$

TABLE 2. Active compound production by Bacillus amyloliquefaciens DH-4 detected by ultraperformance liquid chromatography/electrospray ionization mass spectrometry in positive or negative modes ${ }^{\mathrm{a}}$

\begin{tabular}{|c|c|c|c|c|c|c|c|}
\hline \multirow[b]{2}{*}{ Sample } & \multirow[b]{2}{*}{ Retention (min) } & \multicolumn{2}{|c|}{$\mathrm{m} / \mathrm{z}$} & \multicolumn{2}{|c|}{ Product ions } & \multirow[b]{2}{*}{ MW } & \multirow[b]{2}{*}{ Compound type } \\
\hline & & Pos & Neg & Pos & Neg & & \\
\hline BA1-1 & 4.48 & ND & 623.4 & ND & {$[\mathrm{M}-\mathrm{H}]^{-}$} & 624 & Macrolactin \\
\hline BA1-2 & 5.21 & ND & 433.4 & ND & {$[\mathrm{M}-\mathrm{H}]^{-}$} & 434 & Macrolactin \\
\hline BA1-3 & 5.32 & ND & 433.4 & ND & {$[\mathrm{M}-\mathrm{H}]^{-}$} & 434 & Macrolactin \\
\hline BA1-4 & 5.38 & ND & 501.4 & ND & {$[\mathrm{M}-\mathrm{H}]^{-}$} & 502 & Macrolactin \\
\hline BA2-1 & 4.82 & ND & 741.4 & ND & {$[\mathrm{M}-\mathrm{H}]^{-}$} & 742 & Bacillaene \\
\hline BA2-2 & 4.9 & ND & 741.4 & ND & {$[\mathrm{M}-\mathrm{H}]^{-}$} & 742 & Bacillaene \\
\hline BA2-3 & 5.49 & ND & 579.4 & ND & {$[\mathrm{M}-\mathrm{H}]^{-}$} & 580 & Bacillaene \\
\hline BA2-4 & 5.57 & ND & 581.5 & ND & {$[\mathrm{M}-\mathrm{H}]^{-}$} & 582 & Bacillaene \\
\hline BA3-1 & 5.83 & $1,052.1$ & $1,050.5$ & {$[\mathrm{M}+\mathrm{H}]^{+}$} & {$[\mathrm{M}-\mathrm{H}]^{-}$} & 1,051 & Iturins \\
\hline BA3-2 & 6.17 & $1,080.4$ & $1,078.4$ & {$[\mathrm{M}+\mathrm{H}]^{+}$} & {$[\mathrm{M}-\mathrm{H}]^{-}$} & 1,079 & Iturins \\
\hline BA4-1 & 7.21 & $1,534.2$ & ND & {$[\mathrm{M}+\mathrm{H}]^{+}$} & ND & 1,533 & Fengycin \\
\hline BA4-2 & 7.45 & $1,562.4$ & ND & {$[\mathrm{M}+\mathrm{H}]^{+}$} & ND & 1,561 & Fengycin \\
\hline BA5-1 & 8.15 & 994.7 & 992.5 & {$[\mathrm{M}+\mathrm{H}]^{+}$} & {$[\mathrm{M}-\mathrm{H}]^{-}$} & 993 & Surfactin \\
\hline BA5-2 & 8.37 & $1,008.6$ & $1,006.6$ & {$[\mathrm{M}+\mathrm{H}]^{+}$} & {$[\mathrm{M}-\mathrm{H}]^{-}$} & 1,007 & Surfactin \\
\hline BA5-3 & 8.65 & $1,022.7$ & $1,020.8$ & {$[\mathrm{M}+\mathrm{H}]^{+}$} & {$[\mathrm{M}-\mathrm{H}]^{-}$} & 1,021 & Surfactin \\
\hline BA5-4 & 8.72 & $1,022.6$ & $1,020.4$ & {$[\mathrm{M}+\mathrm{H}]^{+}$} & {$[\mathrm{M}-\mathrm{H}]^{-}$} & 1,021 & Surfactin \\
\hline BA5-5 & 8.82 & $1,022.5$ & $1,020.5$ & {$[\mathrm{M}+\mathrm{H}]^{+}$} & {$[\mathrm{M}-\mathrm{H}]^{-}$} & 1,021 & Surfactin \\
\hline BA5-6 & 8.91 & $1,036.7$ & $1,034.5$ & {$[\mathrm{M}+\mathrm{H}]^{+}$} & {$[\mathrm{M}-\mathrm{H}]^{-}$} & 1,035 & Surfactin \\
\hline
\end{tabular}

a Abbreviations: Pos $=$ positive, $\mathrm{Neg}=$ negative, $\mathrm{MW}=$ molecular weight, and $\mathrm{ND}=$ not determined. 
showed a $99 \%$ homologous identity with B. amyloliquefaciens (accession number NC_023073). The phylogenetic analysis revealed that strain $\mathrm{DH}-4$ 's closest genetic relationship was B. amyloliquefaciens (Fig. 1C).

Antifungal spectrum of $B$. amyloliquefaciens DH-4. B. amyloliquefaciens DH-4 demonstrated broad antifungal activity. with the appearance of inhibitory zones. The fungi used were mainly horticultural pathogens, including several citrus Penicillium spp. diseases, P. expansum (apple blue mold), G. citri-aurantii (citrus sour rot), Alternaria citri (citrus or tomato black rot), Phomopsis citri (citrus stem-end rot), C. gloeosporioides (citrus anthracnose), B. dothidea (kiwi fruit soft rot), and the typical food pathogen Aspergillus niger (Table 1). In addition, strain DH-4 showed prominent suppression of Penicillium digitatum, $P$. italicum, and $P$. ulaiense compared with the others. This indicated that $B$. amyloliquefaciens was very suitable as a significant antagonist in the horticultural field.

Inhibition tests in vivo. The treatment with the culture filtrate strongly suppressed the growth of $P$. digitatum and inhibited the diameter of the lesions (Fig. 2). However, the treatment with the
DH-4 suspension did not have an obvious inhibition effect on citrus green mold. The storage experiments showed that DH-4 cell suspension (noncentrifuged fermentation) and DH-4 supernatant (culture filtrate) could clearly reduce the rot incidence of the fruit. Also, the effect of the DH- 4 cell suspension was better than DH-4 supernatant (Fig. 3; Supplementary Table S1).

The stability of culture filtrate. The culture filtrate retained apparent stability in the inhibition assay. The results showed that the activity of the filtrate against $P$. digitatum was not reduced when treated with either $100^{\circ} \mathrm{C}$ heat or sunlight and UV light. In addition, it maintained excellent antifungal activities under different $\mathrm{pH}$ values. When exposing the filtrate to air for enough time, it still suppressed $P$. digitatum considerably. Therefore, the antifungal compounds were very stable (Fig. 4).

Characterization of the antifungal compounds. The methanol extract showed distinct antifungal activity, which indicated that the antifungal compounds could exist in the methanol fraction. After further purification by UPLC, the fractions at each peak were subjected to ESI-MS analysis. The UPLC/ESI-MS analysis revealed that five types of antimicrobial substances were
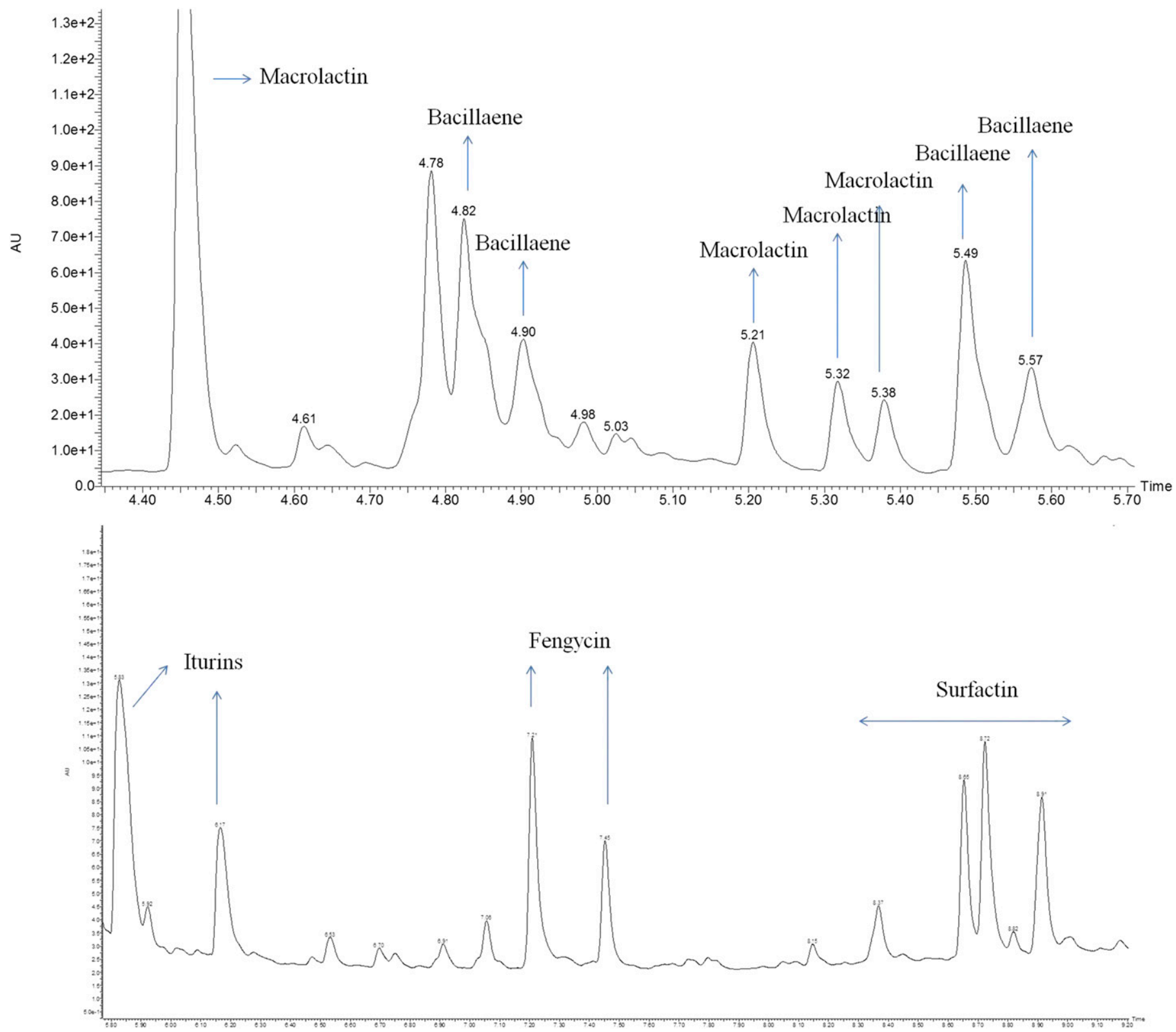

Fig. 5. Ultraperformance liquid chromatography chromatograms of antibiotics produced by Bacillus amyloliquefaciens DH-4. 
detected in the culture filtrate, including macrolactin, bacillaene, iturins, fengycin, and surfactin (Table 2; Figs. 5 and 6). The spectra of the series of BA1 revealed four macrolactin homologs with the molecular masses of $623.4[\mathrm{M}-\mathrm{H}]^{-}, 433.4[\mathrm{M}-\mathrm{H}]^{-}, 433.4[\mathrm{M}-\mathrm{H}]^{-}$, and $501.4[\mathrm{M}-\mathrm{H}]^{-}$in the negative-ion mode (Huang et al. 2014; Nagao et al. 2001). According to ESI-MS data and the previous study, the fractions with $741.4[\mathrm{M}-\mathrm{H}]^{-}, 741.4[\mathrm{M}-\mathrm{H}]^{-}, 579.4$ $[\mathrm{M}-\mathrm{H}]^{-}$, and $581.5[\mathrm{M}-\mathrm{H}]^{-}$were identified as bacillaene, and the nominal molecular weight was 580 (Butcher et al. 2007; Patel et al. 1995). In addition, the members of the lipopeptide family (iturins, fengycin, and surfactin) corresponded to previous reports (Huang et al. 2014; Song et al. 2013; Sun et al. 2006; Yu et al. 2002). The samples BA5-3, BA5-4, and BA5-5 had the same molecular weight of 1,021 and were identified as surfactin geometric isomers (Fig. 6).
Antifungal role of different UPLC fractions. The 17 fractions isolated from the semipreparative UPLC all showed obvious anti- $P$. digitatum effects of different levels. According to the compound identification above, the antifungal compounds in these 17 fractions were preliminarily classified, including the fractions 1, 2, and 4 (macrolactin), 3, 5, and 6 (bacillaene), 7 to 13 (inturins and fengycin), and 14 to 17 (surfactin) (Fig. 7). However, the effect of fractions $8,10,12,13,16$, and 17 was less than that of the others. This test indicated that the macrolactin, bacillaene, and lipopeptide families produced by $B$. amyloliquefaciens were all responsible for the antagonistic activity against $P$. digitatum. In addition, because the antifungal compounds in the culture filtrate were produced in vitro, all of the antifungal compounds in DH-4 were triggered, not after the exposure with $P$. digitatum. These compounds were constitutive in the synthesis of B. amyloliquefaciens.
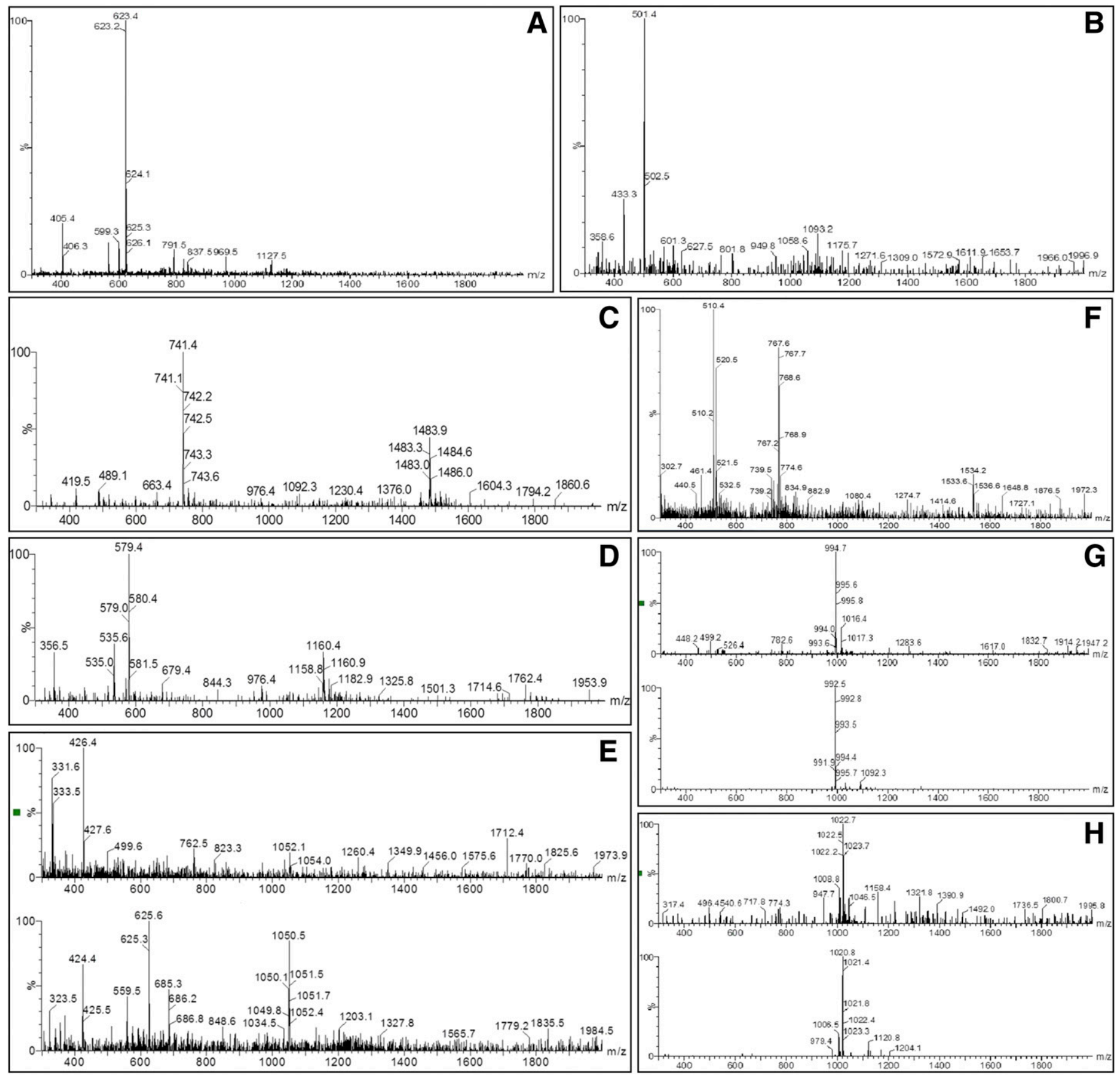

Fig. 6. Mass spectroscopic analysis of antifungal compounds observed in peaks eluted at A, $4.48 \mathrm{~min} ; \mathbf{B}, 5.38 \mathrm{~min} ; \mathbf{C}, 4.82 \mathrm{~min} ; \mathbf{D}, 5.49 \mathrm{~min} ; \mathbf{E}, 5.83 \mathrm{~min} ; \mathbf{F}, 7.21$ $\mathrm{min}$; G, $8.15 \mathrm{~min}$; and $\mathbf{H}, 8.65 \mathrm{~min}$ by ultraperformance liquid chromatography. 
Antifungal role of the heat-killed fractions. After heatkilled treatment, the 17 fractions still showed antifungal activity against $P$. digitatum, which indicated that there heat-tolerant antifungal compounds existed in each of the 17 fractions (Fig. 8). However, the inhibition level changed somewhat. The effect of the fractions 1, 5, 14, and 15 decreased. It was possible that there was some unknown antifungal protein in these three fractions. This test also indicated that most of the antifungal compounds in the culture filtrate were heat tolerant, including macrolactin, bacillaene, and lipopeptide. This result corresponded with the antifungal stability analysis.

SEM observation. Compared with the control group, the treatments with both strain DH-4 and the culture filtrate inhibited mycelia generation at $8 \mathrm{~h}$. The culture filtrate of strain $\mathrm{DH}-4$ showed excellent anti- $P$. digitatum activity, in that the whole growth process of $P$. digitatum was strongly inhibited. From 3 to $8 \mathrm{~h}, P$. digitatum spores were sparse and did not produce mycelia; spores started to form bits of short mycelia at $24 \mathrm{~h}$, and other spores collapsed and some mycelia became fractured and incomplete. At $36 \mathrm{~h}$, many mycelia developed in the wounds, which was certainly related to the quantity and concentration of culture filtrate. The DH-4 suspension showed relatively weaker suppression of $P$. digitatum than the culture filtrate. The presence of mycelia appeared at $24 \mathrm{~h}$. At $36 \mathrm{~h}$, the mycelia displayed a wrinkled property, which was possibly associated with the antifungal metabolites of strain DH-4 (Fig. 9). It was possible that the citrus peel environment was not suitable for the growth of strain $\mathrm{DH}-4$, and few antifungal metabolites were produced. In addition, there was no direct interaction observed between strain DH-4 and $P$. digitatum.

Action site of the antifungal compounds in $P$. digitatum. TEM detection revealed that the addition of the culture filtrate from B. amyloliquefaciens DH-4 caused mitochondrial abnormalities in the mycelia of $P$. digitatum (Fig. 10). The mitochondria in $P$. digitatum degraded, and mitochondrial cristae became gradually disorganized as time progressed. Meanwhile, massive mitochondria became vacuolated along with the leakage of the outer membrane. A prominent feature was vacuole-mediated organelle degradation that
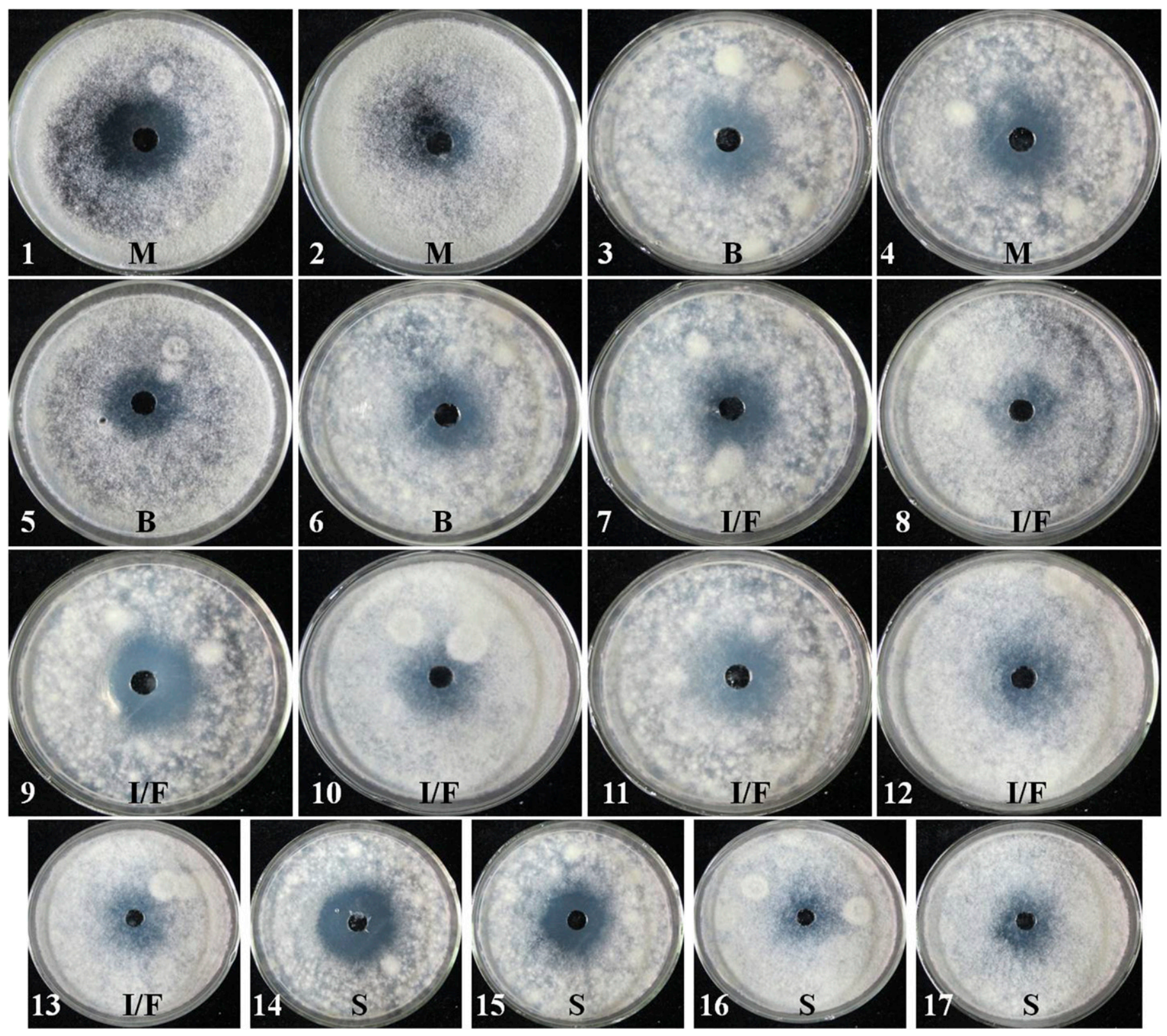

Fig. 7. Antifungal assay of the ultraperformance liquid chromatography (UPLC) fractions. In all, 17 fractions were collected from the semipreparative UPLC system and a bioassay was performed. Numbers 1 to 17 represent the fraction number. Abbreviations M, B, I/F, and S represent the macrolactin, bacillaene, iturins/ fengycin, and surfactin families, respectively. 
appeared in mycelia (Fig. 10) after $2 \mathrm{~h}$ of treatment. These indicated that the antifungal compounds in the culture filtrate came into the cytoplasm of $P$. digitatum and acted on the mitochondria and vacuole, thus damaging the growth of $P$. digitatum.

\section{DISCUSSION}

Strain DH-4 was screened as an antagonist to inhibit postharvest green mold of citrus fruit. Based on morphological observation and molecular identification, strain DH-4 was identified as B. amyloliquefaciens. Because it showed higher antifungal activity against $P$. digitatum compared with many other biocontrol yeasts, B. amyloliquefaciens was given sufficient attention (Arrebola et al. 2010).

B. amyloliquefaciens demonstrated antifungal and antibacterial activities (Sun et al. 2006). The findings of this study further explored the antifungal effects and antifungal spectrum of B. amyloliquefaciens against several plant fungal pathogens. Perhaps because B. amyloliquefaciens used the same culture media (PDA), it produced the same antimicrobial compounds. Therefore, these substances were certain to exhibit different activities against the 17 fungi (Table 1). In addition, the culture filtrate exhibited better antifungal activity than the cell suspension of DH-4 (without culture filtrate) (Fig. 2). This might be because the conditions on the citrus peel were not suitable for the growth and production of the antimicrobial substance by DH-4. However, the storage experiments showed that DH-4 cell suspension (noncentrifuged fermentation) was slightly better than DH-4 supernatant. This might be because the DH- 4 cell suspension contained both $\mathrm{DH}-4$ cells and the culture filtrate. The findings suggest that the culture filtrate with DH-4 in it might be more suitable for controlling green mold in the application. Previous study showed that spore suspension of Paecilomyces lilacinus (noncentrifuged fermentation) achieved higher yield than its cell-free filtrate against Sclerotinia sclerotiorum. Cell suspension of biocontrol agents may continuously produce antifungal substances on plant surfaces, maintaining better suppression efficacy (Bhuiyan et al. 2003; Yang et al. 2015).

The culture filtrate maintained stable antifungal ability against Penicillium digitatum after exposure to UV light, sunlight,
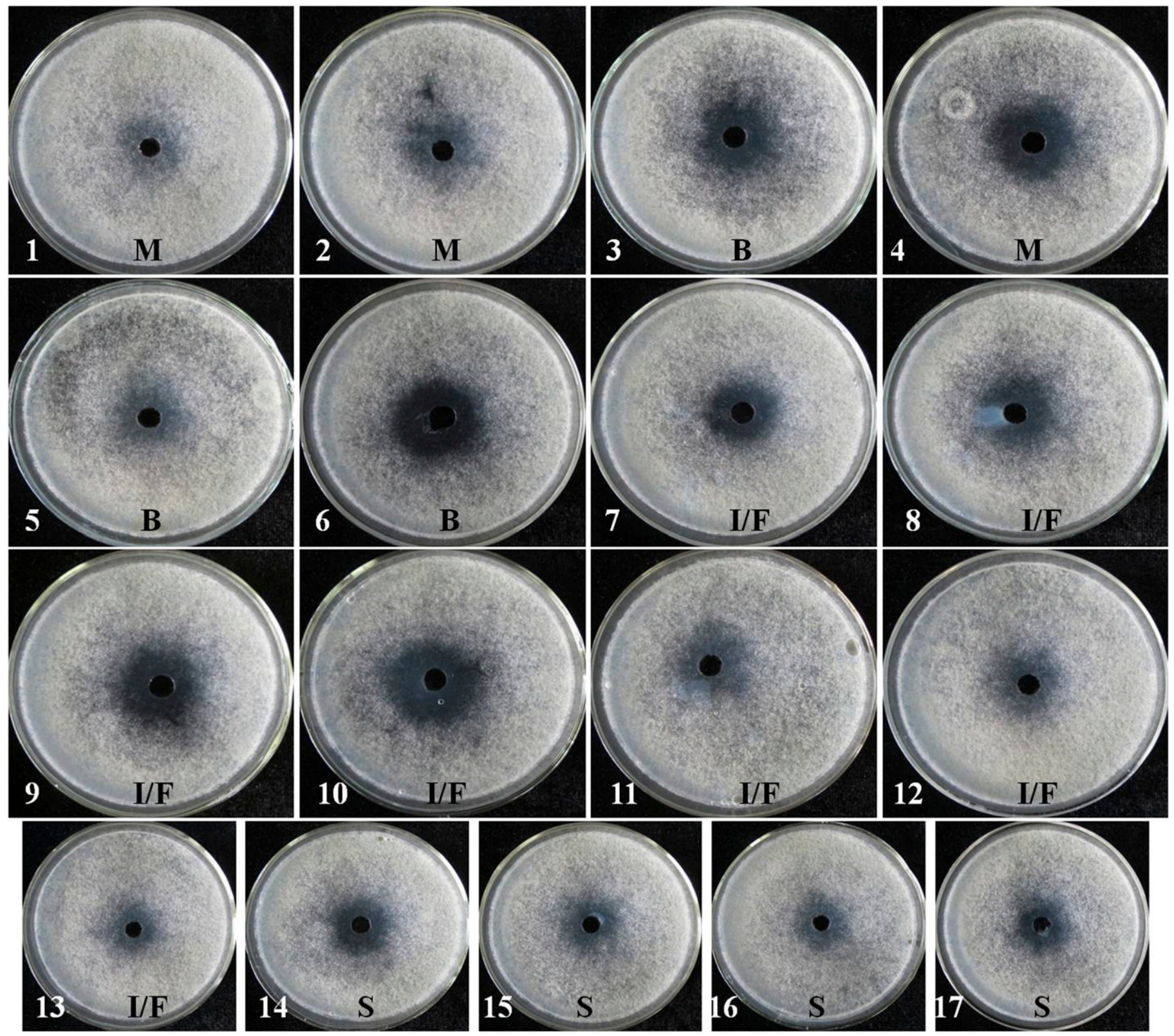

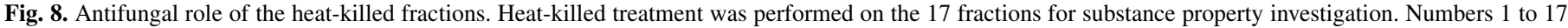
represent the fraction number. Abbreviations M, B, I/F, and S represent the macrolactin, bacillaene, iturins/fengycin, and surfactin families, respectively. 
volatilization, high temperatures, and extreme $\mathrm{pH}$ values (Fig. 4). This indicated that the anti- $P$. digitatum metabolites in the filtrate showed stable antagonists, which were similar to previous reports (Zhao et al. 2013). In addition, once the culture filtrate was applied in the natural environment, it would not be influenced by a change in environmental conditions.

Bacillus spp. usually inhibit microorganisms by producing antimicrobial secondary metabolites, and the antimicrobial substances further cause the death of microorganisms (Hu et al. 2010). These substances are secreted into the culture filtrate, and the technology for identification has been successfully developed. Some of antimicrobial metabolites were determined to be CLP. The CLP family mainly contains surfactins, fengycins, and iturins, which consist of a polypeptide ring connected with a lipid tail of altering length (Falardeau et al. 2013). Two CLP from B. amyloliquefaciens BO5A were tested for their antifungal activities against $F$. oxysporum, A. niger, Botrytis cinerea, and $P$. italicum. In the results, only compound 2 inhibited all pathogens (Romano et al. 2013). Therefore, we can see that every kind of active compound is possibly effective against different pathogens, which probably explains why the filtrate can inhibit $P$. digitatum considerably but $P$. polonicum A1 and others are weakly inhibited in our study. The UPLC/ESI-MS analysis revealed that strain DH-4 could be a coproducer of macrolactin, bacillaene, iturins, fengycin, and surfactin. Also, each of these families was responsible for the

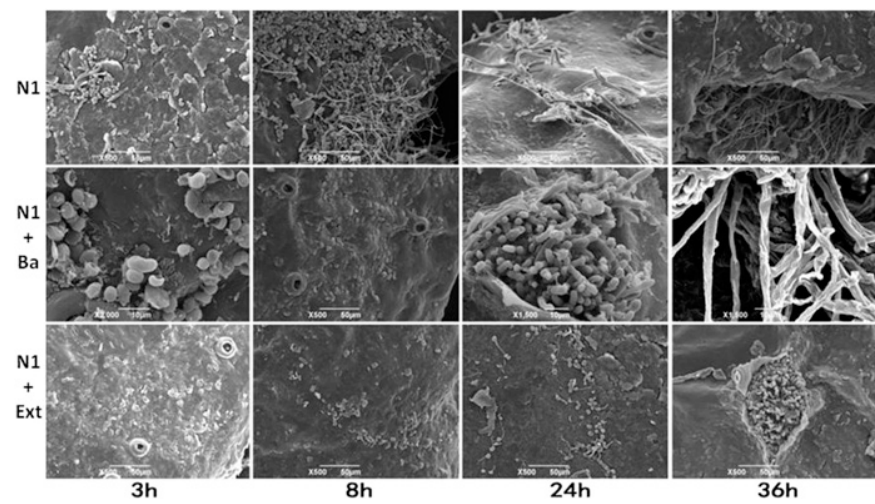

Fig. 9. Scanning electron microscope observation of the inhibitory mechanism of the DH-4 culture filtrate against citrus green mold. Citrus fruit treated with Penicillium digitatum strain N1, $P$. digitatum strain N1 and the strain of DH-4, and $P$. digitatum strain N1 and the culture filtrate of DH- 4 are indicated as N1, $\mathrm{N} 1+\mathrm{Ba}$, and $\mathrm{N} 1+$ Ext, respectively. inhibition effect against $P$. digitatum. These antifungal compounds were constitutive in the synthesis of Bacillus amyloliquefaciens. The $\mathrm{m} / \mathrm{z}$ ratios and molecular weights all corresponded to the previous study. According to the spectra and the available information, the type of the antimicrobial compounds could be deduced.

The antifungal assay in vivo showed that strain DH-4 possibly could produce antifungal substances in citrus fruit but with few quantities suppressing green mold at $8 \mathrm{~h}$. Then, the environment of the citrus peel limited the growth of $B$. amyloliquefaciens. Thus, strain DH-4 could not continue to inhibit P. digitatum (Figs. 2 and 9).

In the analysis of the antagonistic mode of action, the antimicrobial substance produced by $\mathrm{DH}-4$ first caused pathological changes in the mitochondria of the mycelia of $P$. digitatum, including mitochondria abnormalities, vacuolation, leakage of the outer membrane of the mitochondria, and vacuole-mediated organelle degradation (Fig. 10). In a previous report, Kim and Chung (2004) observed that the mode of action of the examined antifungal protein was the disruption of the cell wall. Moreover, several discoveries have demonstrated that an antifungal protein from $B$. amyloliquefaciens (baciamin) can induce membrane permeabilization in fungi (Wong et al. 2008). The main lipopeptide product from $B$. amyloliquefaciens was found to damage the membranes and the whole cells of Vibrio anguillarum (Xu et al. 2014) and Candida albicans (Song et al. 2013). Analogously, we found that the filtrate from the strain DH-4 could restrain the pathogenic effect of $P$. digitatum in citrus fruit. It adequately suppressed the elongation of the mycelia of $P$. digitatum, even breaking them in the early stage. In addition, the experiment (in vivo) showed that the treatment with $\mathrm{DH}-4$ suspension left mycelia of $P$. digitatum completely wilted in $36 \mathrm{~h}$ (Fig. 9). It is probable that the culture filtrate or the antifungal metabolites produced by $B$. amyloliquefaciens DH-4 damages the cell membrane structure of $P$. digitatum. Combining these results above, we can form a hypothesis for the antagonistic mode of action of B. amyloliquefaciens $\mathrm{DH}-4$. The antifungal compounds coming from strain DH-4 probably induce membrane permeabilization in $P$. digitatum, damage cell membranes, and get into the cytoplasm and destroy mitochondria and vacuoles. Ultimately, strain DH-4 achieves the goal of inhibiting the growth and development of $P$. digitatum, even killing it, so that the postharvest green mold of citrus can be effectively controlled.

Further work might evaluate the application or development of strain DH-4 and its filtrate. Several members of the genus Bacillus
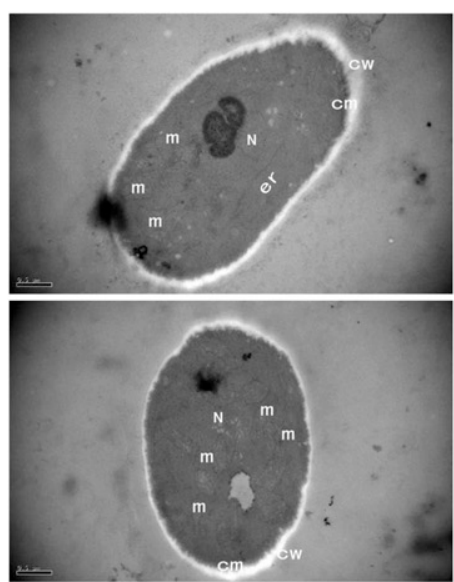

CK
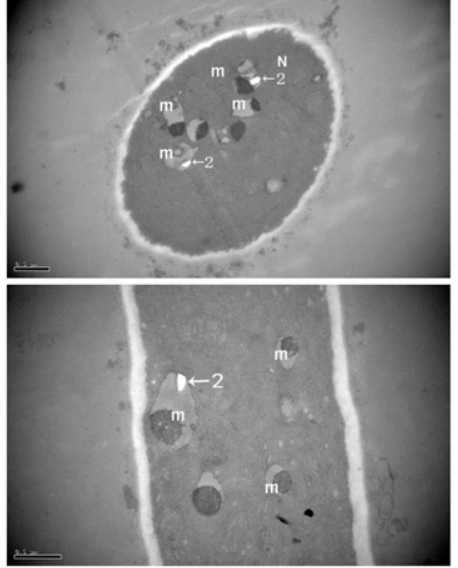

$0.5 \mathrm{~h}$
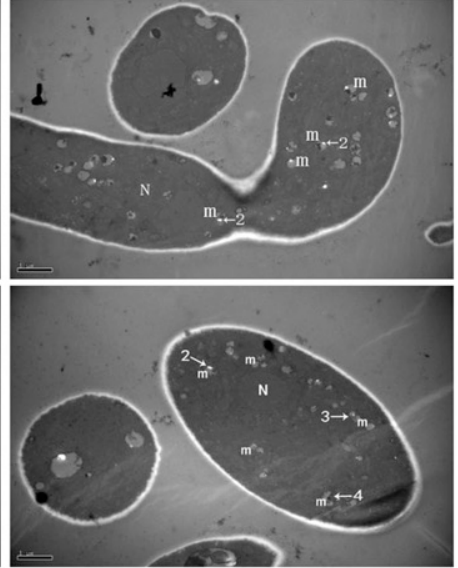

$1 \mathrm{~h}$

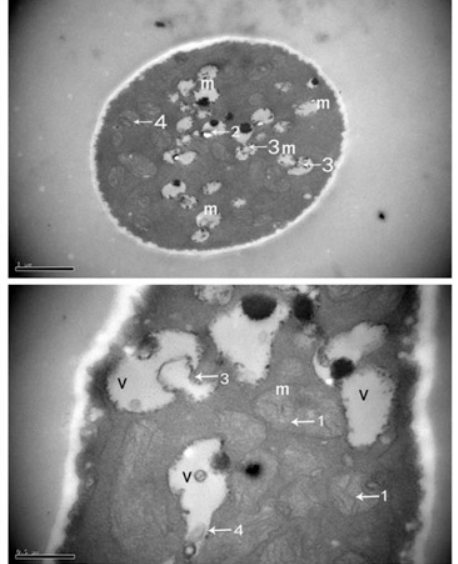

$2 \mathrm{~h}$

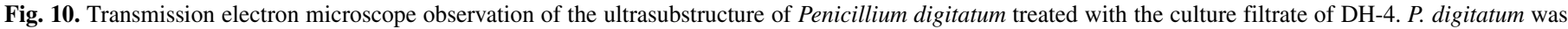

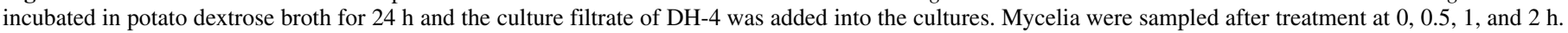

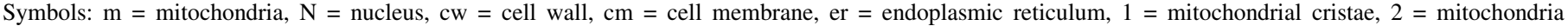
abnormalities and vacuolation, 3 = leakage of the outer membrane of mitochondria, and $4=$ organelle degradation. 
are generally considered safe and have the status of "Generally Recognized As Safe" (Osman et al. 2011). Many products based on Bacillus spp. such as fungicides, bactericides, pesticides, and fertilizers have been marketed. In addition, even Bacillus-based biopesticides have been utilized on a large scale in conventional agriculture (Pérez-García et al. 2011). Applying the filtrate alone might not facilitate the best effect. The combination of B. amyloliquefaciens HF-01 with tea saponin can apparently improve the control efficacy against sour rot and blue and green mold of citrus (Hao et al. 2011). Additionally, the combination of sodium bicarbonate and hot water with HF-01 could significantly inhibit the main postharvest diseases in mandarin fruit and improve the quality of mandarin fruit (Hong et al. 2014). Therefore, the combination of the culture filtrate of strain DH-4 with other additives may be a better approach to control citrus green mold (Yang et al. 2015).

\section{LITERATURE CITED}

Arcas, M., Botia, J., Ortuño, A., and Del Río, J. 2000. UV irradiation alters the levels of flavonoids involved in the defence mechanism of Citrus aurantium fruits against Penicillium digitatum. Eur. J. Plant Pathol. 106:617-622.

Arrebola, E., Sivakumar, D., and Korsten, L. 2010. Effect of volatile compounds produced by Bacillus strains on postharvest decay in citrus. Biol. Control 53:122-128.

Bhuiyan, S. A., Ryley, M. J., Galea, V. J., and Tay, D. 2003. Evaluation of potential biocontrol agents against Claviceps africana in vitro and in vivo. Plant Pathol. 52:60-67.

Butcher, R. A., Schroeder, F. C., Fischbach, M. A., Straight, P. D., Kolter, R., Walsh, C. T., and Clardy, J. 2007. The identification of bacillaene, the product of the PksX megacomplex in Bacillus subtilis. Proc. Natl. Acad. Sci. USA 104:1506-1509.

Falardeau, J., Wise, C., Novitsky, L., and Avis, T. 2013. Ecological and mechanistic insights into the direct and indirect antimicrobial properties of Bacillus subtilis lipopeptides on plant pathogens. J. Chem. Ecol. 39: 869-878.

Hao, W., Li, H., Hu, M., Yang, L., and Rizwan-ul-Haq, M. 2011. Integrated control of citrus green and blue mold and sour rot by Bacillus amyloliquefaciens in combination with tea saponin. Postharvest Biol. Technol. 59: 316-323.

Hong, P., Hao, W., Luo, J., Chen, S., Hu, M., and Zhong, G. 2014. Combination of hot water, Bacillus amyloliquefaciens HF-01 and sodium bicarbonate treatments to control postharvest decay of mandarin fruit. Postharvest Biol. Technol. 88:96-102.

Hu, H. Q., Li, X. S., and He, H. 2010. Characterization of an antimicrobial material from a newly isolated Bacillus amyloliquefaciens from mangrove for biocontrol of Capsicum bacterial wilt. Biol. Control 54:359-365

Huang, J., Wei, Z., Tan, S., Mei, X., Shen, Q., and Xu, Y. 2014. Suppression of bacterial wilt of tomato by bioorganic fertilizer made from the antibacterial compound producing strain Bacillus amyloliquefaciens HR62. J. Agric. Food Chem. 62:10708-10716.

Huang, Y., Wild, B., and Morris, S. 1992. Postharvest biological control of Penicillium digitatum decay on citrus fruit by Bacillus pumilus. Ann. Appl. Biol. 120:367-372.

Janisiewicz, W. J., and Korsten, L. 2002. Biological control of postharvest diseases of fruits. Annu. Rev. Phytopathol. 40:411-441.

Kim, P. I., and Chung, K. C. 2004. Production of an antifungal protein for control of Colletotrichum lagenarium by Bacillus amyloliquefaciens MET0908. FEMS Microbiol. Lett. 234:177-183.

Lai, K., Chen, S., Hu, M., Hu, Q., Geng, P., Weng, Q., and Jia, J. 2012. Control of postharvest green mold of citrus fruit by application of endophytic Paenibacillus polymyxa strain SG-6. Postharvest Biol. Technol. 69:40-48.

Li, X. Y., Yang, J. J., Mao, Z. C., Ho, H. H., Wu, Y. X., and He, Y. Q. 2014. Enhancement of biocontrol activities and cyclic lipopeptides production by chemical mutagenesis of Bacillus subtilis XF-1, a biocontrol agent of Plasmodiophora brassicae and Fusarium solani. Indian J. Microbiol. 54: 476-479.

Liu, P., Cheng, Y. J., Yang, M., Liu, Y., Chen, K., Long, C. A., and Deng, X. X. 2014a. Mechanisms of action for 2-phenylethanol isolated from Kloeckera apiculata in control of Penicillium molds of citrus fruits. BMC Microbiol. 14:242.

Liu, P., Fang, J., Chen, K., Long, C.-a., and Cheng, Y. 2014b. Phenylethanol promotes adhesion and biofilm formation of the antagonistic yeast
Kloeckera apiculata for the control of blue mold on citrus. FEMS Yeast Res. 14:536-546.

Luo, Y., Zeng, K., and Ming, J. 2012. Control of blue and green mold decay of citrus fruit by Pichia membranefaciens and induction of defense responses. Sci. Hortic. (Amsterdam) 135:120-127.

Marcet-Houben, M., Ballester, A. R., de la Fuente, B., Harries, E., Marcos, J. F., González-Candelas, L., and Gabaldón, T. 2012. Genome sequence of the necrotrophic fungus Penicillium digitatum, the main postharvest pathogen of citrus. BMC Genomics 13:646.

Monteiro, L., Mariano, R. L. R., and Souto-Maior, A. M. 2005. Antagonism of Bacillus spp. against Xanthomonas campestris pv. campestris. Braz. Arch. Biol. Technol. 48:23-29.

Nagao, T., Adachi, K., Sakai, M., Nishijima, M., and Sano, H. 2001. Novel macrolactins as antibiotic lactones from a marine bacterium. J. Antibiot. 54: 333-339.

Osman, M. S., Sivakumar, D., and Korsten, L. 2011. Effect of biocontrol agent Bacillus amyloliquefaciens and 1-methyl cyclopropene on the control of postharvest diseases and maintenance of fruit quality. Crop Prot. 30: 173-178.

Patel, P. S., Huang, S., Fisher, S., Pirnik, D., Aklonis, C., Dean, L., Meyers, E., Fernanders, P., and Mayerl, F. 1995. Bacillaene, a novel inhibitor of procaryotic protein synthesis produced by Bacillus subtilis: Production, taxonomy, isolation, physico-chemical characterization and biological activity. J. Antibiot. 48:997-1003

Pérez-García, A., Romero, D., and De Vicente, A. 2011. Plant protection and growth stimulation by microorganisms: Biotechnological applications of Bacilli in agriculture. Curr. Opin. Biotechnol. 22:187-193.

Romano, A., Vitullo, D., Senatore, M., Lima, G., and Lanzotti, V. 2013. Antifungal cyclic lipopeptides from Bacillus amyloliquefaciens strain BO5A. J. Nat. Prod. 76:2019-2025.

Sharma, R. R., Singh, D., and Singh, R. 2009. Biological control of postharvest diseases of fruits and vegetables by microbial antagonists: A review. Biol. Control 50:205-221.

Song, B., Rong, Y. J., Zhao, M. X., and Chi, Z. M. 2013. Antifungal activity of the lipopeptides produced by Bacillus amyloliquefaciens anti-CA against Candida albicans isolated from clinic. Appl. Microbiol. Biotechnol. 97: 7141-7150.

Sun, L., Lu, Z., Bie, X., Lu, F., and Yang, S. 2006. Isolation and characterization of a co-producer of fengycins and surfactins, endophytic Bacillus amyloliquefaciens ES-2, from Scutellaria baicalensis Georgi. World J. Microbiol. Biotechnol. 22:1259-1266.

Szczech, M., and Shoda, M. 2006. The effect of mode of application of Bacillus subtilis RB14-C on its efficacy as a biocontrol agent against Rhizoctonia solani. J. Phytopathol. 154:370-377.

Wong, J., Hao, J., Cao, Z., Qiao, M., Xu, H., Bai, Y., and Ng, T. 2008. An antifungal protein from Bacillus amyloliquefaciens. J. Appl. Microbiol. 105:1888-1898

Xia, H., Fu, W., Chen, M., Huang, Q., Zhao, M., Zhao, Y., Wang, F., and Luo, Y. 2005. The research of rapid DNA extraction from bacteria. Mod. Prev. Med. 32:571-573.

Xu, H. M., Rong, Y. J., Zhao, M. X., Song, B., and Chi, Z. M. 2014. Antibacterial activity of the lipopeptides produced by Bacillus amyloliquefaciens M1 against multidrug-resistant Vibrio spp. isolated from diseased marine animals. Appl. Microbiol. Biotechnol. 98:127-136.

Yánez-Mendizábal, V., Viñas, I., Usall, J., Torres, R., Solsona, C., Abadias, M., and Teixido, N. 2012. Formulation development of the biocontrol agent Bacillus subtilis strain CPA-8 by spray-drying. J. Appl. Microbiol. 112: 954-965.

Yang, F., Abdelnabby, H., and Xiao, Y. 2015. A mutant of the nematophagous fungus Paecilomyces lilacinus (Thom) is a novel biocontrol agent for Sclerotinia sclerotiorum. Microb. Pathog. 89:169-176.

Yu, G. Y., Sinclair, J. B., Hartman, G. L., and Bertagnolli, B. L. 2002. Production of iturin A by Bacillus amyloliquefaciens suppressing Rhizoctonia solani. Soil Biol. Biochem. 34:955-963.

Yuan, B., Wang, Z., Qin, S., Zhao, G. H., Feng, Y. J., Wei, L. H., and Jiang, J. H. 2012. Study of the anti-sapstain fungus activity of Bacillus amyloliquefaciens CGMCC 5569 associated with Ginkgo biloba and identification of its active components. Bioresour. Technol. 114:536-541.

Zhang, D., Xia, R., Cao, X., Shu, B., and Chen, C. 2013. Root hair development of Poncirus trifoliata grown in different growth cultures and treated with 3 -indolebutyric acid and ethephon. Sci. Hortic. (Amsterdam) 160: 389-397.

Zhao, Y., Li, P., Huang, K., Wang, Y., Hu, H., and Sun, Y. 2013. Control of postharvest soft rot caused by Erwinia carotovora of vegetables by a strain of Bacillus amyloliquefaciens and its potential modes of action. World $\mathbf{J}$. Microbiol. Biotechnol. 29:411-420. 